\title{
EVALUATION OF EXTRA AXIAL CEREBELLOPONTINE ANGLE TUMOURS THROUGH MRI
}

\author{
BISWAS PK ${ }^{1}$, SARDAR MH ${ }^{2}$,SAHA GC ${ }^{3}$, HOSSAIN MZ ${ }^{4}$, HOSSAIN MS ${ }^{5}$, PAUL T ${ }^{6}$, AZAD KAK ${ }^{7}$
}

\begin{abstract}
:
Aim: This study aimed to evaluate the incidence of extra-axial cerebellopontine angle tumours and to characterize extra-axial cerebellopontine angle tumours.

Methods: The study was carried out in Dhaka Medical College for the duration of 2 years from July 2016 to July 2018. All patients with clinical suspicion of CP angle tumours subjected 1.5 T MR imaging system. Total 30 patients were evaluated during this period.

Results: Extra-axial CPA tumours accounts for 7-10\% of brain tumours. Most common extraaxial CPA tumour is schwannoma (60\%), followed by meningioma (27\%), epidermoid (7\%), arachnoid cysts (7\%). 51-60 years is the most common age group involved. Schwannomas are common extra-axial CPA tumours which are enhancing round masses most commonly arise from the vestibular nerve and associated with enlargement of the internal auditory canal. Meningiomas are the second most common extra-axial CP angle tumours which oval or hemispheric lesions with a broad attachment to tentorium or petrous dura matter.

Conclusion: MRI is the most sensitive noninvasive modality to characterize extra-axial CPA tumours. MRI identifies the location and extension of the lesions based on their characteristic signal and enhancement pattern on contrast.
\end{abstract}

Keywords: Extra-Axial, Cerebellopontine, Brain tumour, MRI

J Dhaka Med Coll. 2018; 27(2) : 104-107

\section{Introduction}

The cerebellopontine angle (CPA) cistern is a subarachnoid space containing cranial nerves and vessels bathed in cerebrospinal fluid (CSF). The CPA is bounded by the pons, the anterior aspect of the cerebellum and the petrous temporal bone covered by dura mater. Tumours of the cerebellopontine angle (CPA) comprise $10 \%$ of all intracranial tumours ${ }^{1,2}$

Vestibular schwannomas account for $70 \%-80 \%$ of all CPA lesions, meningiomas $5-12 \%$ and epidermoid cysts $2-6 \%$, other lesions, which accounts every $\mathrm{d} " 1 \% 1,2,3$. Tumours derived from various anatomical structures, includes primary origin from internal auditory meatus, pontocerebellar cistern and lateral recess of the 4th ventricle, temporal bone, brain stem, or cerebellar nervous tissue ${ }^{4,5,6}$

Clinical presentation of the CPA tumours is variable and it depends upon the size and location of the tumour. It can be asymptomatic in early stage or it can give vertigo, tinnitus, or

1. *Dr. Prodip Kumar Biswas, Associate Professor of Medicine, Dhaka Medical College, Dhaka

2. Dr. Md. Hafiz Sardar, Professor of Medicine, Dhaka Medical College.

3. Dr. Gopal Chandra Saha, Assistant Professor, Department of Radiology and Imaging, Institute of Child and Mother Health, Dhaka.

4. Dr. Mohammad Zaid Hossain, Associate Professor of Medicine, Dhaka Medical College, Hospital, Dhaka

5. Dr. Mohammed Shahadat Hossain, Assistant Professor of Medicine, OSD, DGHS. Attached to Faridpur Medical College, Faridpur

6. Dr. Tushit Paul, Honorary Medical Officer, Dept. of Medicine, Dhaka Medical College Hospital, Dhaka

7. Prof. Khan Abul Kalam Azad, Professor and Head, Dept. of Medicine, Dhaka Medical College, Dhaka

*Correspondence: Dr. Prodip Kumar Biswas, Associate Professor of Medicine, Dhaka Medical College, Dhaka Mobile: 01816828895. Email: prodipaurko@gmail.com

Received: 12 May 2018

Revision: 26 August 2018

Accepted: 08 September 2018

https:/ / doi.org/ 10.3329/jdmc.v27i2.45818 
hearing loss. Vascular compression of the vestibule-cochlear nerve also causes vertigo and tinnitus.

Computerized tomography (CT) and magnetic resonance imaging (MRI) are the primary modalities for diagnosis of cerebellopontine lesions. MRI is considered superior in differentiating the different types of CPA masses.

\section{Material and Methods}

Patients attending the Department of Radiology, Dhaka Medical College, Dhaka was the main source of data for this study. All patients referred to the Department of Radiology with clinical suspicion of CPA tumours for the duration of 2 years from July 2016 to July 2018 subject for study. A total of 30 patients were enrolled in this study. Patients from all age groups who are clinically suspected to have ICSOL were included and patient having a history of claustrophobia, metallic implants insertion, cardiac pacemakers were excluded from this study.

\section{Results:}

Thirty patients were evaluated, whose age group ranged from 10 to 90 years. The highest incidence of extra-axial $\mathrm{cp}$ angle tumours was found in 51-60 years age group accounting for $29 \%$ of cases and least was seen in the age group of 11-20years constituting 4\%. Thirty patients were evaluated of which $9(30 \%)$ were males and $21(70 \%)$ were females. Out of the 30 patients who were evaluated, schwannoma $(60 \%)$ is the most common pathology followed by meningioma $(26.7 \%)$, epidermoid $(6.7 \%)$, arachnoid cysts $(6.7 \%)$. The most common extra-axial CP angle tumour is schwannoma with 18 cases $(60 \%)$. This was followed by meningioma with 8 cases $(26.7 \%)$, followed by epidermoid and arachnoid cysts with 2 cases each (6.7\%). Extra-axial CP angle tumors are more common above 4 th to 5 th decade. Peak age incidence noted in 5 th to the 6 th decade with 8 cases $(26.7 \%)$.

Table-I

Age incidence of various extra and CP angle tumors

\begin{tabular}{lccccccccc}
\hline Tumor type & $10-20$ & $21-30$ & $31-40$ & $41-50$ & $51-60$ & $61-70$ & $71-80$ & $81-90$ & Total \\
\hline Schwannoma & 1 & 2 & 2 & 3 & 4 & 3 & 3 & 0 & 18 \\
Meningioma & 0 & 0 & 1 & 1 & 3 & 1 & 1 & 1 & 8 \\
Arachnoid cyst & 0 & 1 & 1 & 0 & 0 & 0 & 0 & 0 & 2 \\
Epidermoid cyst & 0 & 0 & 1 & 0 & 0 & 1 & 0 & 0 & 2 \\
\hline Total & 1 & 3 & 5 & 4 & 7 & 5 & 4 & 1 & 30 \\
\hline
\end{tabular}

Table-II

Presenting symptoms and number of patients

\begin{tabular}{lcccc}
\hline Symptoms & $\begin{array}{c}\text { Schwannoma } \\
(\mathrm{n}=18)\end{array}$ & $\begin{array}{c}\text { Meningioma } \\
(\mathrm{n}=8)\end{array}$ & $\begin{array}{c}\text { Arachnoidx } \\
(\mathrm{n}=2)\end{array}$ & $\begin{array}{c}\text { Epidermoid } \\
(\mathrm{n}=2)\end{array}$ \\
\hline Hearing loss & 14 & 3 & 0 & 0 \\
Tinnitus & 7 & 2 & 1 & 1 \\
Headache & 10 & 3 & 2 & 2 \\
Dizziness & 6 & 1 & 2 & 0 \\
Facial numbness & 2 & 0 & 0 & 0 \\
Diplopia & 1 & 0 & 0 & 0 \\
\hline
\end{tabular}


Out of 18 cases of Schwannoma 4 cases in 5 th to 6 th decade followed by 3 cases each in 4 th, 6 th and 7 th decades. Out of 8 cases Meningioma 3 cases in 5 th to 6 th decade. Out of 30 cases of extra-axial CPA tumours 21 cases are female $(70 \%)$, males 9 cases $(30 \%)$ with a female preponderance, female: male ratio being 2.3:1 (Table 1).

Out of 18 cases of Schwannoma 12 cases of females, 6 cases of males, out of 8 cases of Meningioma 6 cases of females, 2 cases of males, 2 cases of arachnoid cysts of females, 1 case of epidermoid cyst is male and another case is female. So, there is a female preponderance in extra-axial CPA tumours.

Majority of the patients shows headache and dizziness. Majority of the Schwannoma patients shows hearing loss, headache, tinnitus, and dizziness (Table 2).

Out of 18 cases of Schwannoma 7 case shows homogenous enhancement (39\%), 11 cases show heterogenous enhancement $(61 \%)$ on contrast. Out of 8 cases of Meningioma 7 case shows homogenous enhancement $(87 \%), 1$ case shows heterogeneous enhancement $(13 \%)$ on contrast. Out of 2 cases of each arachnoid cyst and epidermoid cyst follows CSF signal intensity on T1, T2, and FLAIR (Figure 1 and Figure 2). Diffusion restriction in 2 cases $(100 \%)$ of the epidermoid cyst, no restriction in 2 cases of arachnoid cysts.

\section{Discussion}

In our study of MR imaging of extra-axial cp angle tumors, we evaluated 30cases. Out of Thirty patients evaluated schwannoma diagnosed in 18 cases (60\%). Among the 18 cases, Males were 6 and Females were 12 with a female to male ratio 2.3:1. A maximum number of patients in the age group of 50-60yrs constituting $40 \%$ of patients. Unilateral involvement is seen in 17 cases and bilateral involvement is noted in 1 case, which is a case of Neurofibromatosis type II with multiple vestibular schwannomas in cp angle, Meckel's cave, lateral walls of cavernous sinuses and Neurofibromas in the spinal canal. The commonly involved location is the vestibular component of VIII nerve, then facial and trigeminal nerves. In this study, 17 cases of vestibular schwannoma (89.4\%) and 1 case of trigeminal schwannoma were recorded.

Previous studies reported that schwannomas arise from the vestibulocochlear nerve, is more often than the other cranial nerve and the vestibular division is more commonly involved than the cochlear division ${ }^{7,8}$.

The literature reported that vestibular schwannomas account 8 to $10 \%$ and $60-90 \%$ of total CPA tumors ${ }^{9,10}$. In the current study, the common lesion observed was vestibular schwannoma, accounts for $53.3 \%$ in total, which was consistent with the previous studies.

One case of trigeminal schwannoma encountered in this study. Hodgson TJ et al ${ }^{11}$ reported that signal intensity of the masses on MRI will not contribute to the accurate radiographic diagnosis of the intracanalicular meningioma.

In the present study, one lesion was showed both solid and cystic components. Both the lesions showed marked enhancement on postcontrast sequences. Similar findings were described by Valavanis A et $\mathrm{a}^{12}$

On T1, most tumors are isointense to the cortical grey matter (from 56\% to 94\%). Hypointense meningiomas account from 20\% to $48 \%$, and hyperintense tumors on T1weighted images are rare. On T2-weighted images, about $50 \%$ of the tumors remain isointense with the brain cortex. Hypointense tumors are less common, from $4 \%$ to $18 \%$, whereas hyperintense lesions account for $35 \%$ to $44 \% 22,23$.

In the present series, on T1-weighted images, Out of 8 cases of Meningioma 5 cases were Isointense $(62.5 \%), 2$ cases hypo-intense $(25 \%), 1$ caseshowmixedintensity (12.5\%). On the T2-weighted images, Out of 8 cases of Meningioma in 6 cases were hyperintense $(75 \%), 1$ case was isointense $(12.5 \%) 1$ case show mixed intensity $(12,5 \%)$ to the cortical grey matter.

In our study, all the meningiomas showed enhancement after contrast administration, Out of 8 cases of Meningioma 7 case shows 
homogenous enhancement (87\%), 1 case shows heterogeneous enhancement (13\%) on contrast.

Nakau et al., ${ }^{13}$ studied the correlation of the MR imaging and histopathological findings in nine cases of meningiomas with a dural tail sign. They suggested that tumour cell nests in the dura-mater of those patients, making the surgical resection of these areas mandatory. Almost $35 \%$ of the patients with meningiomas may present the dural tail signal on postcontrast $\mathrm{T} 1$-weighted images ${ }^{14}$. In the present series, this sign was seen frequently, being identified in $50 \%$ of the patients.

\section{Conclusion}

A spectrum of usual and unusual lesions exists in the $\mathrm{CP}$ angle. Among extra-axial CP angle tumours acoustic schwannomas are most common tumours at $\mathrm{CP}$ angle followed by meningiomas. Signal intensity on MR imaging, enhancement, shape and margins, extent, mass effect and adjacent bone reaction are also helpful in establishing the diagnosis. MRI is the most sensitive non-invasive modality in the characterization of extra-axial $\mathrm{cp}$ angle tumours. It can identify the site and extension of the lesions as well as the characteristic signal and enhancement pattern on contrast. Apart from diagnosing, MR imaging plays an important role in stratifying patients into appropriate treatment options.

\section{References}

1. Moffat DA, Ballagh RH. Rare tumours of the cerebellopontine angle. Clin Oncol (R Coll Radiol) 1995; $7(1): 28-41$.
2. Brunori A, Scarano P, Chiappetta F. Non-acoustic neuroma tumor (NANT) of the cerebellopontine angle: A 15-year experience. J Neurosurg Sci 1997;41 (3):159-68.

3. Bonneville F, Sarrazin JL, Dupuch KM, Iffenecker C, Cordoliani YS, Doyon D, Bonneville JF. Unusual Lesions of the Cerebellopontine Angle: A Segmental Approach. Radiographics 2001;21 (5):419-38.

4. Schaller B. Cerebellopontine angle surgery. Part 1: General remarks. HNO 2003;51 (6):284-95.

5. Brackmann DE, Kwartler JA. A review of acoustic tumors: 1983-1988. Am J Otol 1990; 11 (2):216-32.

6. Smirniotopoulos JG, Yue NC, Rushing EJ. Cerebellopontine angle masses: Radiologic-pathologic correlation. Radiographics 1993;13 (4):1131-47.

7. Clemis JD, Ballad WJ, Baggot PJ, Lyon ST. Relative frequency of inferior vestibular schwannoma. Arch Otolaryngol Head Neck Surg. 1986;112(2):190- 194.

9 Valavanis A, Schubiger O, Naidich T. Clinical imaging of the cerebellopontine angle. Berlin: SpringerVerlag; 1987.

10 Artels LJ, Arrington JR. Rare tumors of the cerebellopontine angle. In: Jackler RK, Brackmann D, editors.Neurotology. St. Louis: Mosby; 1994. pp. 835- 861 .

11 Hodgson TJ, Kingsley DP. Meningioma presenting as a mass in the internal auditory canal. Neuroradiology. 1995;37:479-480.

12 Mulkens TH, Parizel PM, Martin JJ, et al. Acoustic schwannoma: MR findings in 84 tumors. AJR. 1993;160:395-398.

13 Nakau H, Miyazawa T, Tamai S, et al. Pathologic significance of meningeal enhancement ("flare sign") of meningiomas on MRI. Surg Neurol 1997;48 (4):584- 590.

14 Atlas SW. Magnetic resonance imaging of the brain and spine. Philadelphia: Lippincott Willians and Wilkins, 2002. 14 